\title{
Stacked Two Layer Dualband Antenna for Wireless Applications
}

\author{
Savita C. Raut \\ Assistant Professor, K.J. Somaiya College of Engineering, Vidyavihar (E), Mumbai \\ *Email: savitasonukale@Somaiya.edu
}

\section{Received: 09 ${ }^{\text {th }}$ July 2018, Accepted: $14^{\text {th }}$ August 2018, Published: $31^{\text {st }}$ August 2018}

\begin{abstract}
This paper proposes a Stacked Two Layer Rectangular Microstrip Antenna (RMSA) structure for Wireless applications in IEEE $802.11 \mathrm{a} / \mathrm{ac} / \mathrm{n}$. The proposed antenna consists of two rectangular patches fabricated on two different layers FR4 substrate, separated by an air gap. An Upper patch acts as radiating antenna which is parasitically coupled with lower patch. The Lower patch is fed with 50 ohms coaxial cable. The antenna is simulated using Method of Moments (MoM) based IE3D software. The proposed structure effectively covers two bands $4.98 \mathrm{GHz}-7.51 \mathrm{GHz}$ and $8.35 \mathrm{GHz}$ $-9.09 \mathrm{GHz}$. The simulated VSWR is $<2$ over the entire range in both the frequency bands. The radiation patterns show the suitability of the Antenna for wireless applications.
\end{abstract}

Keywords: Dual Band, RMSA, Upper/Radiating Patch, Lower/Feed Patch, IEEE 802.11, Air Gap

\section{Introduction}

Broadband microstrip antennas are widely used in many wireless applications. The microstrip antenna has inherently low bandwidth. Many techniques have been reported to increase the bandwidth of microstrip antenna [6].These techniques include monopole microstrip antenna and inserting slots in in regular shaped patches. Several structures have been proposed for monopole configurations and slot antenna [1-3]. Bandwidth can be increased by making use of thicker substrates and lowering the dielectric constant [6].Use of thick substrates increases the probe length of feed probe, which deteriorate the antenna performance due to spurious radiations from feed-probe. Making use of air gap in multi-layer configuration ensures increase in height of the antenna and reduction in effective dielectric constant. Multilayer antenna structures are also reported along with slotted patch [4-5]. Thus many complex antenna structures have been reported to cover wideband for WLAN applications. This paper introduces a simpler RMSA structure in stacked configuration. The use of air gap between the two substrate layers yields wide impedance bandwidth with the return loss well below $-9.5 \mathrm{~dB}(\mathrm{VSWR}<2$ ) over the entire range.

\section{Design Methodology}

Single layer RMSA was first designed at the resonant frequency of $5.5 \mathrm{GHz}$ with FR-4 substrate of height $1.59 \mathrm{~mm}$. The antenna was simulated with IE3D software. It was observed that the antenna has the impedance bandwidth of $300 \mathrm{MHz}$ between 5.14 to $5.4 \mathrm{GHz}$. In order to improve bandwidth of the antenna, a parasitic patch was added to yield a stacked two layer structure. The two layer antenna was simulated and optimized to obtain dual band operation with improved bandwidth.

\section{Stacked Antenna Configuration}

The antenna structure consists of stacked two layer RMSA configuration as shown in fig 1. The upper patch dimensions are $\mathrm{L} 1=11.0 \mathrm{~mm}, \mathrm{~W} 1=16.6 \mathrm{~mm}$ and for the lower patch $\mathrm{L} 2=11.4 \mathrm{~mm}, \mathrm{~W} 2=16.6$ $\mathrm{mm}$. Height of the antenna is $6.18 \mathrm{~mm}$ with $\mathrm{h} 1=\mathrm{h} 2=$

$1.59 \mathrm{~mm}$ with an air gap of $3 \mathrm{~mm}, \varepsilon_{\mathrm{r} 1}=\varepsilon_{\mathrm{r} 2}=4.4$. The antenna is fed with $50 \mathrm{ohm}$ coaxial probe feed at the lower patch. Fig. 2 shows a three dimensional view of the simulated antenna structure. The antenna also yields a wideband operation by varying an air gap and upper patch length. Parametric study of the antenna was done to study the effect of air gap and feed point on lower patch.

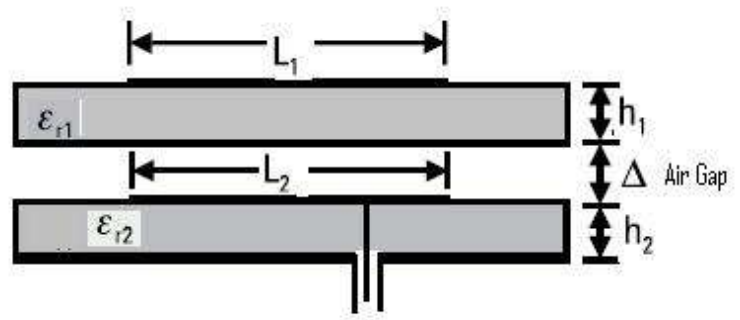

Fig. 1 Side View of the Proposed Stacked

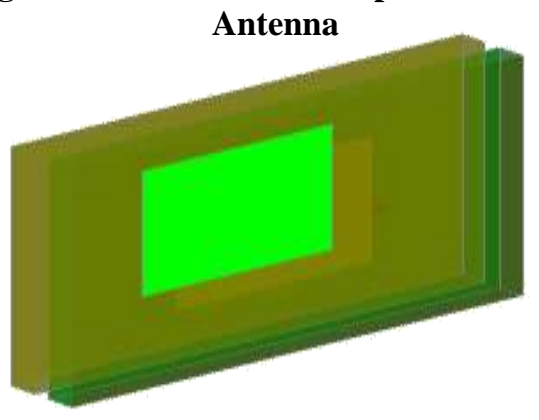

Fig 2 3-D View of the Proposed Stacked Antenna 


\section{Simulation Results}

The Antenna is simulated with IE3D 12.0 software, to determine the performance parameters such as return loss, VSWR, Smith chart showing impedance variation and the radiation patterns at resonant frequencies. The effect of variation of various parameters of the antenna such as air gap, L1 and L2 were investigated.

\section{Return Loss}

It is observed that the antenna yields the two bands $4.98 \mathrm{GHz}-7.51 \mathrm{GHz}$ and $8.35 \mathrm{GHz}-9.09 \mathrm{GHz}$ from the return loss variation as shown in fig.

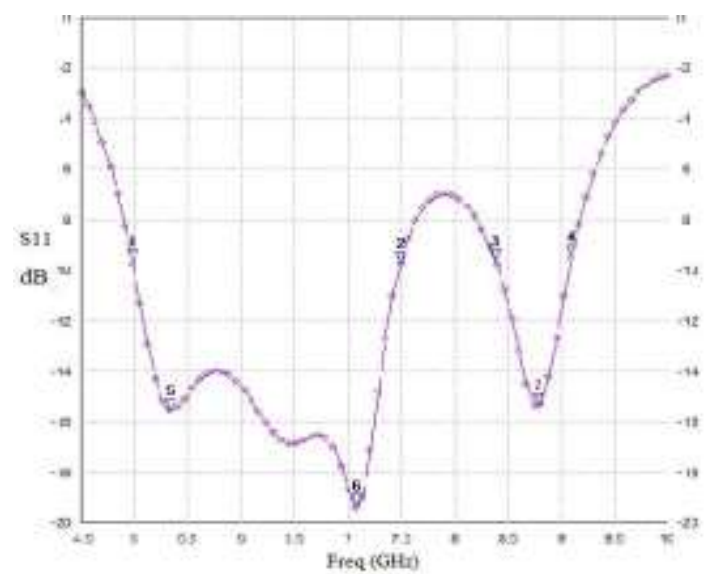

Fig 3(a) Simulated Return Loss Curve

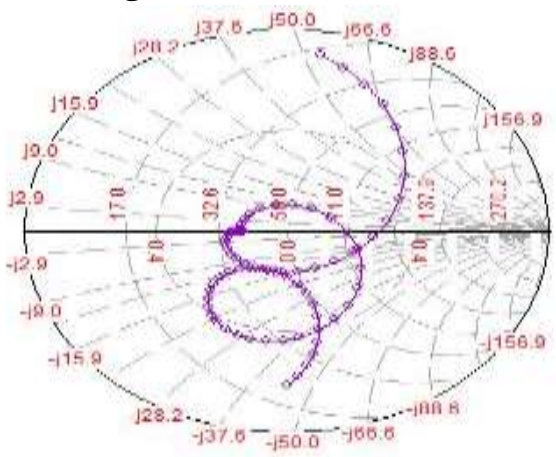

Fig 3(b) Impedance Variation

\section{Current Distribution}

Current distributions of upper and lower patches at the resonant frequencies in both the bands is presented in fig 4. From the current distributions, it can be observed that frequency band-1 $(5.33 \mathrm{GHz}$ and $7.05 \mathrm{GHz})$ is mainly due to lower patch and mutual coupling effect between two patches. Frequency Band-2 $(8.77 \mathrm{GHz})$ is the result of lower patch.

Radiation Characteristics and Gain of Antenna Fig 5 (a) shows the radiation3-dimensional radiation pattern of proposed Antenna for Total Electric field E-Total followed by 2-Dimensional E-field and $\mathrm{H}$-field Radiation patterns .As shown in fig 5 (d). The Antenna exhibits gain of around $6 \mathrm{~dB}$ in band-1 which is approximately constant over an entire band-1.

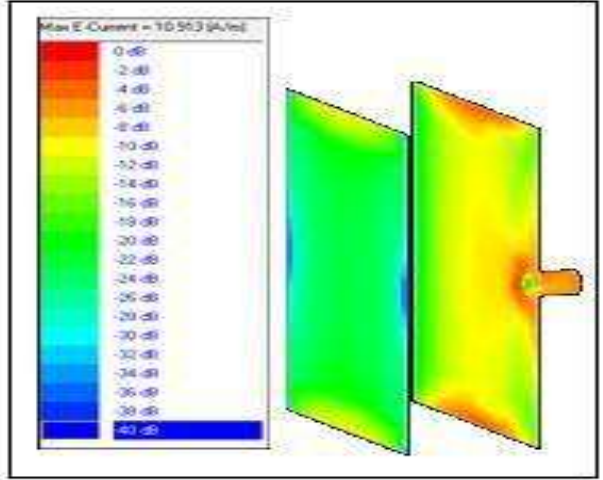

Fig. 4 (a) Current Distribution at $5.33 \mathrm{GHz}$

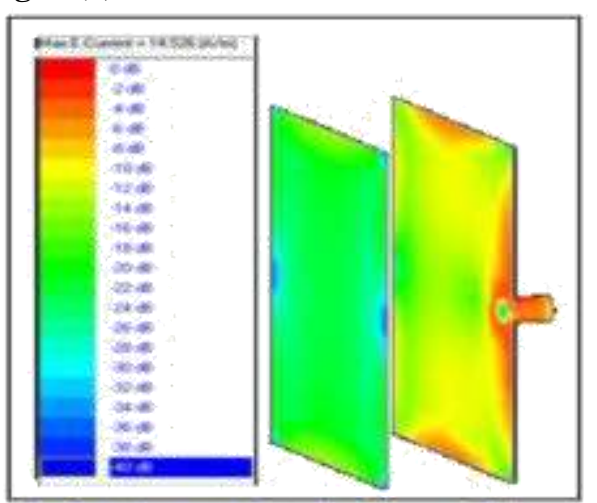

Fig. 4 (b) Current Distribution at 7.05 GHz

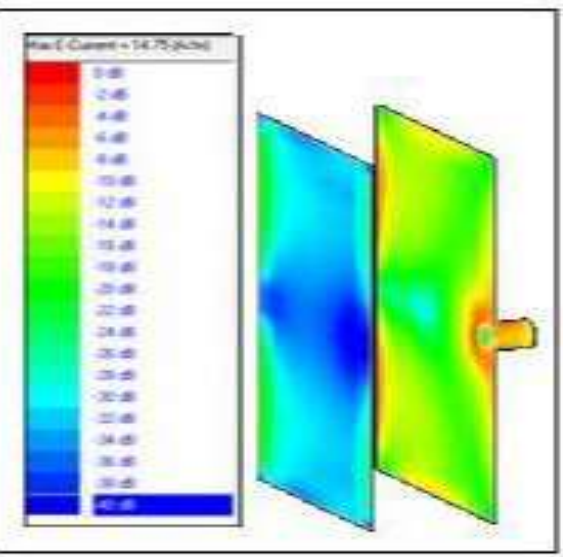

Fig 4 (c) Current Distribution at $8.77 \mathrm{GHz}$

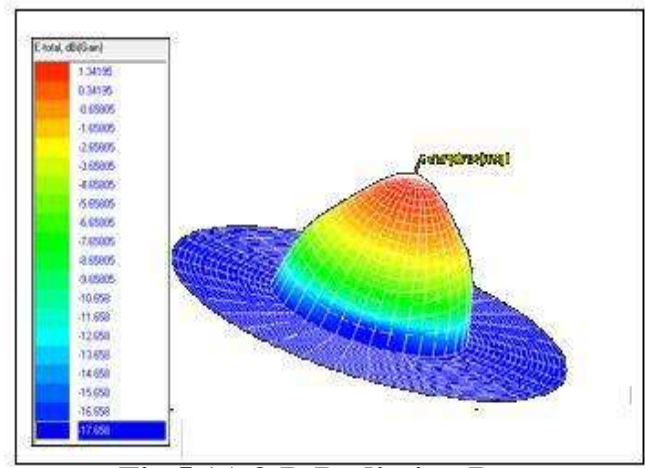

Fig 5 (a) 3-D Radiation Pattern 
Helix Vol. 8(5): 3954- 3956

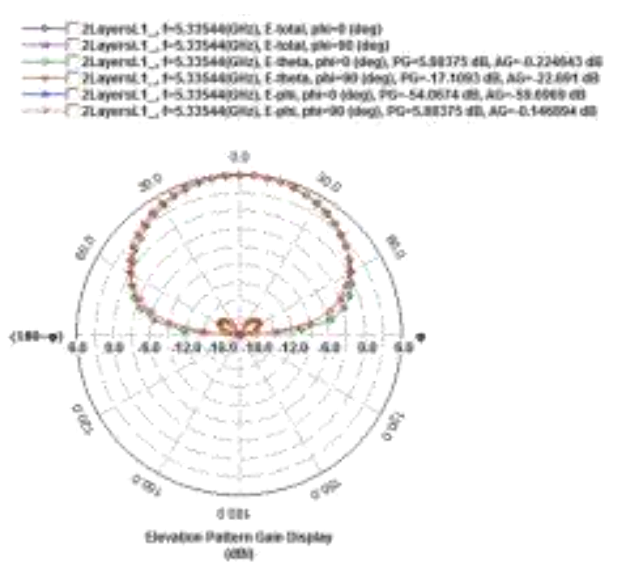

Fig 5 (b) at $5.33 \mathrm{GHz}$

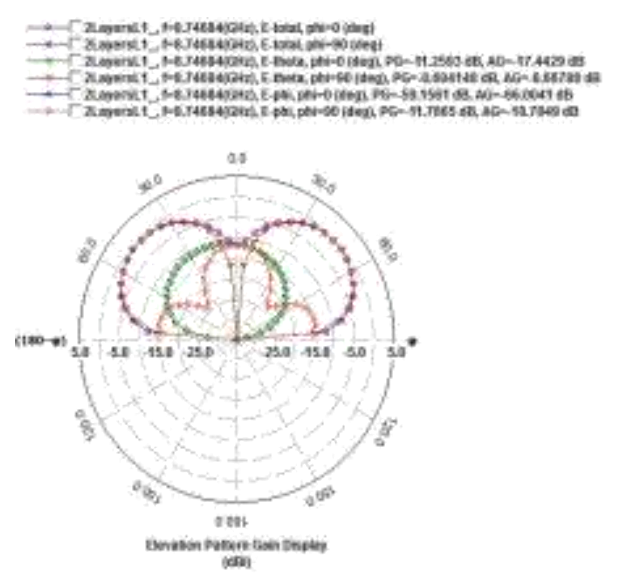

Fig 5 (C) at $7.05 \mathrm{GHz}$
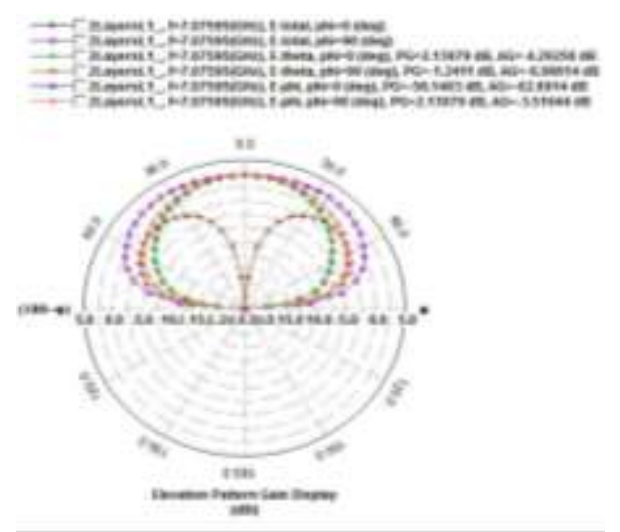

Fig 5 (d) at $8.77 \mathrm{GHz}$

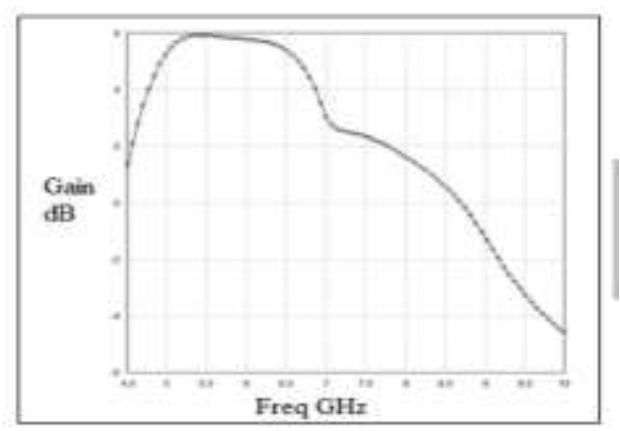

Fig 5 (e) Frequency versus Gain of Antenna

\section{Conclusion}

Proposed Antenna is low profile and can be easily fabricated using commonly available FR-4 substrate. The parametric study of the antenna is also carried out to investigate the effect of air gap. The simulation results show good agreement with the return loss of $-15.57 \mathrm{~dB}$, $-19.35 \mathrm{~dB}$ and $-15.37 \mathrm{~dB}$ at the resonant frequencies of $5.33 \mathrm{GHz}, 7.05 \mathrm{GHz}$ and $8.7 \mathrm{GHz}$ respectively. The Antenna exhibits a wide band operation with VSWR bandwidth of $2.53 \mathrm{GHz}(4.98-7.51 \mathrm{GHz})$ in band-1 and $740 \mathrm{MHz}(8.35-9 \mathrm{GHz})$ in band-2. The antenna covers part of C-band and X-band frequency ranges. Thus the proposed antenna covers wide range of applications such as WLAN and C and X-band applications. The Future work will be focused on the modifying the parasitic patch the to investigate multiband and wideband operations.

\section{References}

1. Ratikanta Sahoo, D. Vakula, and N. V. S. N. Sarma. -A Wideband Conformal Slot Antenna for GPS Applicationll, Progress in Electromagnetics Research Symposium - Fall (PIERS - FALL), Singapore, 1922 November 2017

2. Biao Li, Yang Ding, Yang Zeng Yin, -A Novel DualBand Circularly Polarized Rectangular Slot Antennall, International Journal of Antennas and Propagation, Article ID 9071610, Volume 2016

3. M. Tecpoyotl-Torres and J. G. Vera-Dimas, -Dual band Pentagonal Microstrip Antenna for Wi-Fi Applicationsl, 2010 Electronics, Robotics and Automotive Mechanics Conference.

4.Vinay Sharma, Rajesh Kumar Vishwakarma -A Stacked Microstrip Antenna For Multiband ApplicationsllIEEE International Conference on Computer, Communication and Control (IC42015).

5. M. A. Matin, B. S. Sharif, and C. C. Ts imenidis.-Probe Fed Stacke Patch Antenna for Wideband 